\title{
Surgical collateralization: The hidden mechanism for improving prognosis in chronic coronary syndromes
}

Torsten Doenst, $\mathrm{MD}, \mathrm{PhD},{ }^{\mathrm{a}}$ and Holger Sigusch, $\mathrm{MD}^{\mathrm{b}}$

Video clip is available online.

Feature Editor's Introduction-In this issue of the Journal, Doenst and Sigusch nicely summarize the mechanisms of the protective effect of coronary bypass surgery on the coronary circulation and on clinical outcomes. Although percutaneous interventions treat only flow-limiting stenoses, bypass surgery confers long-term protection against disease progression in the entire grafted vessel ("surgical collateralization"). This key mechanistic difference likely explains the difference in outcomes between the 2 strategies and has profound implications for many aspects of modern coronary bypass practice, including the use of arterial grafts and the role of fractional flow reserve. Although the evidence summarized by the authors is not necessarily recent, Doenst and Sigusch's elegant review is an important reminder for the surgical community of the foundations and potential of the most commonly performed cardiac surgery operation, and I am sure that many readers, like me, will enjoy reading it.

\section{Mario Gaudino, MD, MSCE}

Coronary artery disease (CAD) causes ischemia by the generation of stenosing lesions in the vessel wall that gradually limit (chronic/inducible ischemia) or suddenly interrupt blood flow by complete vessel occlusion (acute ischemia, the main mechanism of acute myocardial infarction). ${ }^{1}$ As a consequence, disease conditions associated with CAD are separated into acute or chronic coronary syndromes (the latter was formerly referred to as "stable CAD").,

Treatment of CAD generally consists of medical therapy (a combination of beta-blockers, renin-angiotensin-

\footnotetext{
From the ${ }^{\mathrm{a}}$ Department of Cardiothoracic Surgery, Jena University Hospital, Friedrich Schiller University of Jena, Jena, Germany; and ${ }^{\mathrm{b}}$ Department of Cardiology, Heinrich-Braun Klinikum, Zwickau, Germany.

Received for publication July 27, 2020; revisions received Oct 2, 2020; accepted for publication Oct 7, 2020; available ahead of print Nov 10, 2020.

Address for reprints: Torsten Doenst, MD, PhD, Department of Cardiothoracic Surgery, Jena University Hospital, Am Klinikum 1 D - 07747, Jena, Germany (E-mail: doenst@med.uni-jena.de).

J Thorac Cardiovasc Surg 2022;163:703-8

0022-5223/ $\$ 36.00$

Copyright (C) 2020 by The American Association for Thoracic Surgery

https://doi.org/10.1016/j.jtcvs.2020.10.121
}

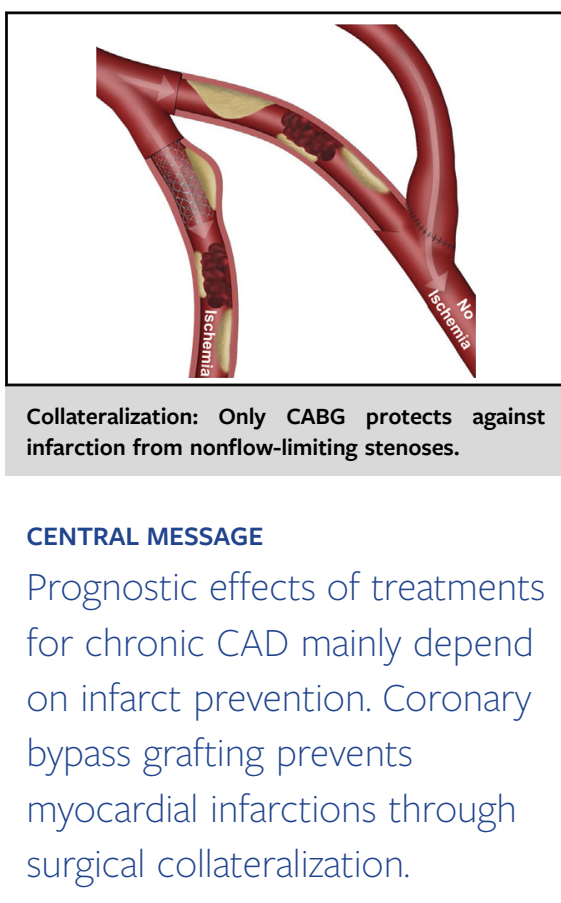

See Commentaries on pages 709 and 710.

aldosterone system inhibitors, platelet inhibition, statins, and other cholesterol-lowering drugs together with lifestyle modifications) with the option of adding invasive treatment modalities, specifically percutaneous coronary intervention (PCI) and coronary artery bypass grafting (CABG). ${ }^{2}$ Because the limitation or interruption of blood flow to the distal myocardium is the main mechanism of CAD, treatments directed at improving or restoring blood flow have been summarized under the term of "myocardial revascularization." $^{,-4}$

There is no doubt that revascularization is key for the treatment of acute ischemia. ${ }^{5}$ For chronic coronary syndromes, it has been accepted that the detection of ischemia (by single photon emission computed tomography, cardiac magnetic resonance tomography, or FDG-positron emission tomography) and the assessment of flow relevance of individual stenoses (by fractional flow reserve [FFR], intravascular ultrasound, or OCT) are helpful guides for applying and choosing the optimal revascularization strategy., However, despite its plausibility and worldwide acceptance, the available evidence supporting a life-prolonging effect of revascularization for chronic coronary syndromes appears less convincing than for acute coronary syndromes and appears contradictory. ${ }^{1}$ 


\section{CONTROVERSIAL EVIDENCE FOR INVASIVE CORONARY ARTERY DISEASE TREATMENT}

Prospective randomized evidence addressing the impact of revascularization through PCI in patients with chronic coronary syndromes has not yet convincingly demonstrated a prognostic benefit. ${ }^{6,7}$ Although symptomatic relief is one key goal of revascularization, ${ }^{3}$ even this effect has recently been questioned by the controversially discussed ORBITA trial, in which classic stenting was not associated with a measurable difference in symptom relief compared with mock PCI to the left anterior descending. ${ }^{8}$ In addition, the most recent trial $^{9}$ assessing a strategy of early invasive diagnosis followed by revascularization for chronic coronary syndrome versus a conservative medical strategy reconfirmed the lack of a prognostic impact of revascularization. The trial failed to demonstrate a survival difference to medical therapy for the invasive group, which consisted of three-quarters of patients who underwent PCI and onequarter of patients who underwent CABG.

In contrast, there is repeated evidence from prospective randomized trials that $\mathrm{CABG}$ provides a survival benefit over $\mathrm{PCI}^{10}$ and medical therapy. ${ }^{11}$ However, this advantage appears to be especially present in patient populations who are characterized by higher severity of CAD and the presence of other cardiovascular comorbidities such as diabetes mellitus or heart failure. ${ }^{1,12,13}$ These conditions are generally associated with higher risk of myocardial infarctions. The only prospective randomized comparison of CABG to medical therapy was performed in patients with ischemic heart failure. The Surgical Treatment of IsChemic Heart
Failure trial randomized patients with impaired left ventricular function (ejection fraction $<35 \%$ ) to CABG or medical therapy. Patients in the CABG group lived on average 18 months longer compared with medical therapy over a 10-year observation period. ${ }^{11}$ Neither ischemia ${ }^{14}$ nor viability testing ${ }^{15}$ was associated with the treatment effect of CABG on survival. Thus, both diagnostic tools were not helpful for decision-making.

Therefore, one may conclude that if PCI does not prolong life and if ischemia testing is not helpful for achieving improvements in prognosis in chronic coronary syndromes, the life-prolonging effect of CABG appears to be mediated through a mechanism that is not directly related to revasularization.

\section{SURGICAL COLLATERALIZATION: IMPROVING SURVIVAL BY PREVENTING MYOCARDIAL INFARCTIONS}

We previously suggested that the survival advantage of CABG is linked to the ability of bypass grafting to reduce the incidence of new myocardial infarctions. ${ }^{1}$ Figure 1 shows this effect for the majority of current randomized trials having compared CABG with PCI (Table E1). It also receives support from a plethora of recent reports that we recently reviewed. ${ }^{16}$ We suggested that a patent graft to a distal coronary artery creates a surgical collateral that may prevent the occurrence of a new infarction in case the vessel occludes proximal to bypass insertion (eg, by a ruptured plaque). ${ }^{1}$ The mechanism of action is then similar to a collateral stemming from angiogenesis

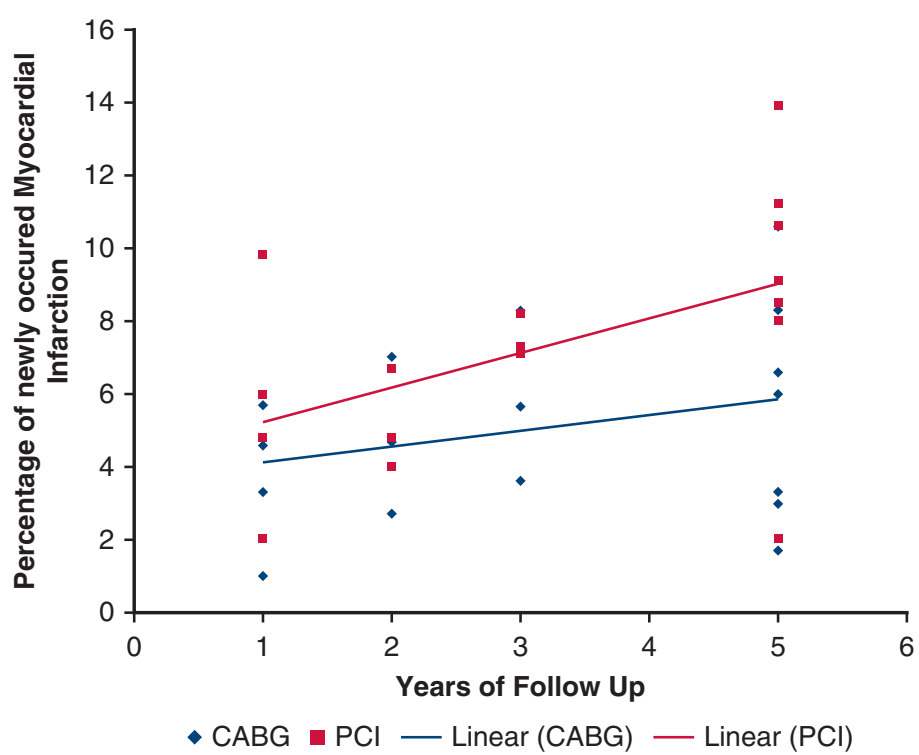

FIGURE 1. Incidence of myocardial infarction in patients who received PCI or CABG in current prospective randomized trials as reported by the trials at different time points (references including the values of the individual studies are listed in Table E1). Note that in these randomized patient populations, CABG was associated with fewer myocardial infarctions (independent of differing definitions of myocardial infarction used in the different trials). $C A B G$, Coronary artery bypass grafting; $P C I$, percutaneous coronary intervention. 
or arteriogenesis. Figure 2 schematically illustrates this concept. In addition to PCI, CABG not only revascularizes chronically ischemic myocardium caused by a significant stenosis but also prevents new myocardial infarctions that may originate from other nonflow-limiting lesions in the same vascular bed. The spatial distance of vessel occlusions and bypass graft insertion was analyzed by Jeon and colleagues, ${ }^{17}$ who compared 168 patients after CABG with 208 patients presenting with ST-segment elevation myocardial infarction. They quantified the median distance between vessel occlusion and graft insertion, which ranged between 11 and $49 \mathrm{~mm}$ depending on the grafted vessel (Figure 2), and suggested that CABG thereby protects against infarction. We suggested that this protective effect is not primarily due to the resupply of blood to chronically ischemic myocardium but by establishing an alternative pathway for blood flow in case the original vessel occludes (ie, surgical collateralization). ${ }^{1}$ The Video 1 shows an angiographic example where a 13-year-old vein graft supplies a coronary territory that no longer receives blood from the meanwhile occluded

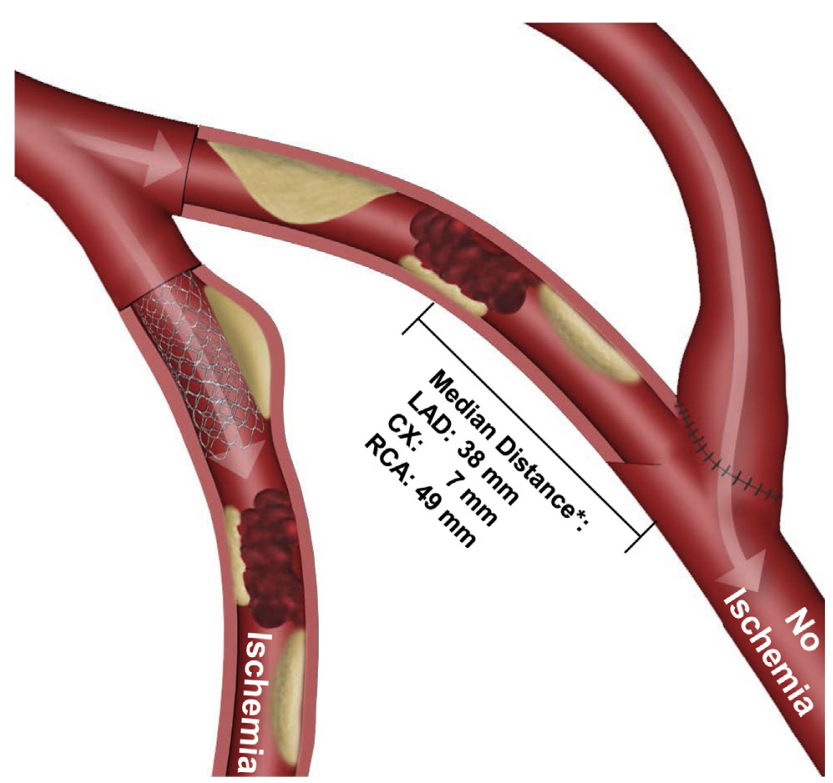

FIGURE 2. Schematic illustration of the concept of surgical collateralization. Both PCI and CABG treat ischemia by directly eliminating the flowlimiting lesion (PCI) or by circumventing it with a bypass graft (CABG). However, because the majority of myocardial infarctions are caused by nonflow-limiting lesions, the collateral created by bypass grafting can additionally protect against infarction from nonflow-limiting stenoses. The arrows indicate blood flow to the distal myocardium, which is maintained through the bypass graft if a nonflow-limiting lesion causes native vessel occlusion. *The values reflect a median distance from vessel occlusion to bypass graft insertion as assessed in a comparative study of 168 patients who underwent $C A B G$ and 200 patients with acute myocardial infarction. ${ }^{17} L A D$, Left anterior descending; $C X$, circumflex; $R C A$, right coronary artery.

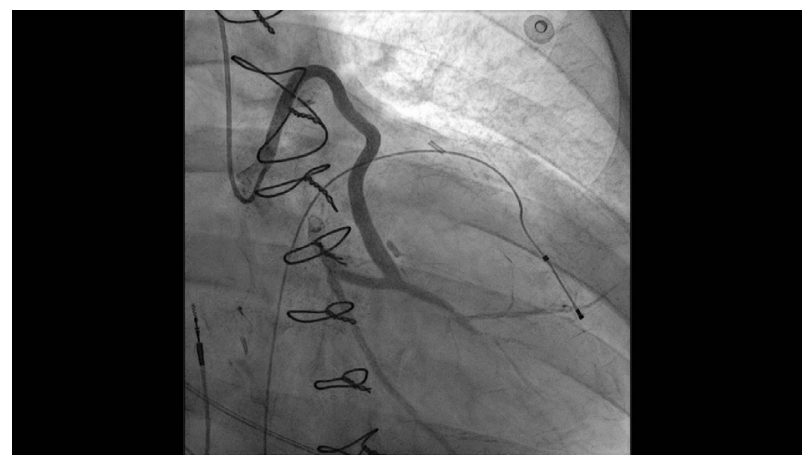

VIDEO 1. Angiographic sequence of a 13-year-old vein graft supplying a posterolateral branch of the circumflex artery. Note the occluded native circumflex artery despite the presence of a stent. Video available at: https://www.jtcvs.org/article/S0022-5223(20)33044-0/fulltext.

native vessel, but the myocardium did not suffer an infarction from the occlusion of this native vessel.

We further illustrated in our review that the majority $(>85 \%)$ of myocardial infarctions are linked to nonflowlimiting lesions. ${ }^{1}$ Figure 3 quantifies the occurrence of myocardial infarctions based on the degree of vessel stenoses before vessel occlusion. Severe stenoses (presumably flow-limiting) were the cause for myocardial infarction in less than $15 \%$. Thus, focusing PCI to only flow-limiting lesions, as recommended to improve PCI outcomes, ${ }^{3,18}$ thereby limits PCI's ability to prevent new myocardial infarctions. The result should be greater protection against new myocardial infarction from CABG than from PCI.

The currently available data suggest that the treatment of chronic ischemia by normalizing blood flow (ie, revascularization) may primarily alleviate symptoms, but that prevention of new myocardial infarctions (eg, by surgical collateralization) may prolong life.

\section{SURGICAL COLLATERALIZATION IS PARADIGM SHIFTING}

The summarized recognition is paradigm shifting, but it also explains the majority of perceived controversies in the literature. The following 6 points address the main consequences that arise from it and explain the main current controversies.

\section{Current terminology appears inappropriate}

With the suggestion that an infarct-prevention mechanism (eg, surgical collateralization) prolongs life rather than revascularization of chronic ischemic myocardium, ${ }^{1}$ the term "myocardial revascularization" for summarizing the invasive treatment options appears, scientifically speaking, inappropriate because the term suggests a presumed mechanism that may prevent the consideration of additional or alternative mechanisms. The term "invasive treatment of CAD" whether by PCI or CABG, may be 


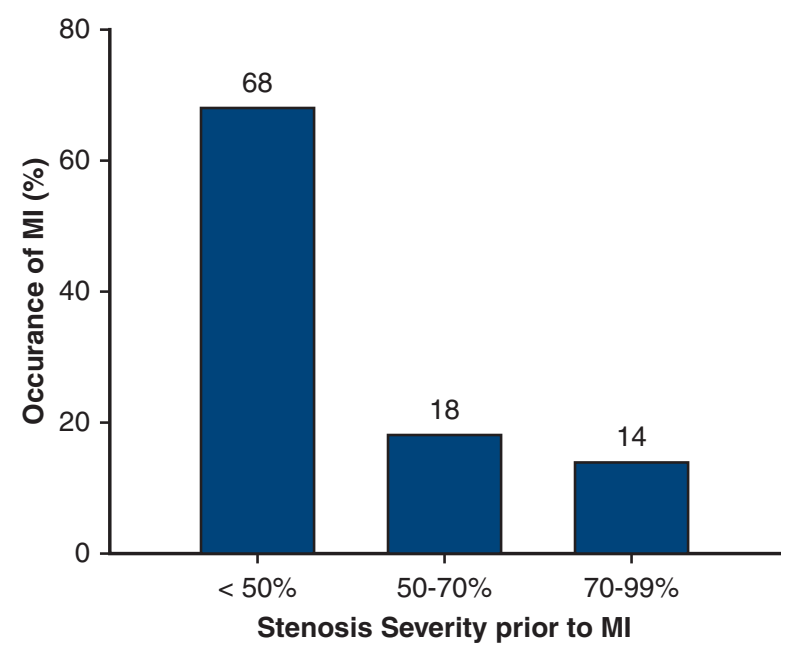

FIGURE 3. Occurrence of myocardial infarction and stenosis severity based on serial angiographic examinations. The majority of myocardial infarctions evolve from plaques that are only mildly to moderately obstructive. Graphs are constructed from previous data. ${ }^{1} M I$, Myocardial infarction.

more appropriate because it does not suggest a presumed mechanism (ie, revascularization) and allows the presence of alternative mechanisms of action (eg, surgical collateralization). A similar rationale regarding the semantics of long-established terminology resulted in the change of the term "stable CAD" to "chronic coronary syndrome."

\section{Patient consenting may require revision}

Patients with multivessel disease are required to be discussed by a heart team. ${ }^{3}$ This joint recommendation is then supposed to be presented to the patient to reach the final treatment decision, which is certainly influenced by many different factors. Future informed consent may now require explaining the difference between revascularization and surgical collateralization. This difference no longer supports offering the choice between " 2 types of revascularization." It would require information on 1 less-invasive treatment option restoring blood flow by treating flowlimiting (primarily symptom-causing) lesions and 1 more invasive treatment option providing both restoration of adequate blood flow (ie, revascularization) and significant protection against new myocardial infarctions (ie, surgical collateralization).

\section{Grafts must stay patent}

One key condition for exploiting the described mechanisms of CABG is graft patency. Graft occlusion obviously eliminates any revascularizing and infarct-preventative effects. Two main directions are currently being followed to achieve this task. First, multiarterial revascularization has been associated with better graft patency and better survival. ${ }^{19}$ Considering that the majority of patients undergoing $\mathrm{CABG}$ in comparative trials compared with PCI received 1 left internal thoracic artery plus veins (which is consistent with current daily practice in most surgical centers worldwide) illustrates how large the therapeutic potential of multiple arterial CABG may be. It is interesting to note in this context, that the 10-year survival curves for PCI and CABG in the SYNTAX trial did not further diverge after 5 years. ${ }^{13}$ Although not evaluated, it is conceivable that graft occlusions may have contributed to this result. The ROMA trial, comparing multiple arterial revascularization with a strategy of left internal thoracic artery plus veins on a large scale, will provide definitive answers to this question. $^{20}$

Second, it has been suggested to use FFR assessment to guide coronary bypass target selection. Several smaller trials have been performed with different results. ${ }^{21-23}$ FFR guidance resulted in the performance of fewer grafts without significantly affecting patency rates. ${ }^{21,23}$ From a "surgical collateralization perspective," the omission of targets would result in less protection against future infarctions. ${ }^{1}$ In other words, more open grafts should result in more protection against myocardial infarction. Assessing the distances from infarction sites to graft insertions (Figure 2) underscores this suggestion. It is further supported by coronary computed tomography investigations in patients after CABG. ${ }^{24,25}$ These authors found that the number of unprotected coronary territories (ie, myocardial regions at risk not supplied with an open bypass graft) correlated with prognosis. Although these findings may argue against using FFR for target selection, FFR assessment may still be useful in CABG. High FFR values reflect a higher risk of graft occlusion, but all evidence thus far supports that graft occlusions in the context of high FFR values are not associated with clinical events. The occlusions appear to occur silently. ${ }^{21-23,26,27}$ However, the occlusion risk appears to depend on the type of graft (vein or artery) and the technical construction of the grafts (single vs sequential grafts). ${ }^{26,27}$ Therefore, FFR assessment may be helpful in determining the best strategy for obtaining the highest rate of long-term patent grafts.

\section{Better stents will probably not lead to better survival}

One of the typical arguments used for explaining the lack of prognostic impact of PCI has been the use of older stents. However, on the basis of the recognitions listed, stent type should not make a difference in survival. Newergeneration drug-eluting stents have successfully reduced the rate of re-revascularizations,,${ }^{3,28}$ but they never provided a survival advantage over bare metal (older) stents or medical therapy. ${ }^{1,6,7,9,28}$ On the basis of the considerations that contemporary PCI in chronic coronary syndrome only addresses the minority of infarct-causing lesions (Figure 3), it is statistically challenging to detect an infarctpreventative effect of PCI in clinical trials. In addition, 
even the finding of fewer myocardial infarctions with PCI in some trials may not translate into a survival impact. ${ }^{18,29}$ Thus, the infarct-preventative potential with CABG appears greater (Figure 2) and may additionally be supported by the consequent use of the left internal thoracic artery to the left anterior descending artery, a graft that has excellent longterm patency to a vessel that supplies the largest part of the myocardium and in which occlusions likely cause deadly infarctions. ${ }^{30}$ Any potential prognostic effect of PCI over medical therapy (as suggested by a recent network metaanalysis $^{31}$ ) can again be associated with a lower incidence of myocardial infarction in this group. ${ }^{1}$ Thus, the link between infarct prevention and prognosis may be prevailing for PCI; only the chance to achieve it is smaller than with CABG. This notion may also explain our possibly conflicting report in which we demonstrate a survival benefit for PCI in a retrospective propensity-matched comparison with medical therapy once the amount of single photon emission computed tomography detected ischemia exceeded $15 \% .{ }^{32}$ This study is currently the only report demonstrating a survival impact for isolated PCI (not mixed with CABG) in chronic coronary syndromes. However, we were not able to provide information on CAD severity and the incidence of myocardial infarctions. Although our data in this anal$y$ sis $^{32}$ are from an all-comers registry and likely contain many patients who are not necessarily part of generally highly selected randomized trials, we cannot exclude the possibility that the survival effect again is mediated by infarct prevention. Nevertheless, the data may also serve to support a prognostic impact of revascularization (ie, the resupply of blood to chronically ischemic territories), but considering the vast body of evidence in this field, ${ }^{1,3}$ this effect would appear to be smaller for prognosis than the one preventing new infarctions.

\section{Medical therapy is complementary to CABG}

Medical therapy has made tremendous progress over time. Recent reports suggest that the main effects are again mediated though infarct prevention mainly through cholesterol-lowering strategies (and not so much by betablockers). ${ }^{33,34}$ The effects are complementary as illustrated by the survival advantage of CABG over medical therapy in the Surgical Treatment of IsChemic Heart Failure trial. ${ }^{11}$ Considering that patients after CABG are often less well medically treated compared with patients after PCI, ${ }^{35}$ it appears important for surgeons to stress this point. Optimal medical therapy in patients after CABG is likely to further improve CABG outcomes.

\section{CAD assessment must change}

Despite all criticism raised in this article regarding our understanding of the presumed mechanisms and our terminology for $\mathrm{CABG}$ and PCI, the current guidelines provide a good practical guide for decision-making. This is specifically true when all operative and interventional risks as well as long-term aspects such as graft patency and stent complications are considered. However, our ability to identify infarct-prone lesions is still wanting. Although new interventional techniques such as intravascular ultrasound, near-infrared spectroscopy, and OCT may provide new ways to identify infarct-prone lesions, ${ }^{3,36}$ the advent of coronary computed tomography, computed tomography FFR, ${ }^{37}$ and risk scores such as the Duke CAD score ${ }^{38}$ or the Leaman score ${ }^{1,3,37}$ may be attractive noninvasive diagnostic tools that allow for better decision-making in the heart team of the future. Coronary computed tomography-derived approaches identifying unprotected coronary territories at risk correlate with prognosis in patients after $\mathrm{CABG}$. $^{24,25}$

\section{CONCLUSIONS}

CABG provides a comprehensive treatment of CAD by revascularization of ischemic myocardium plus surgical collateralization for infarct prevention by placing a bypass graft distal to the majority of CAD lesions. Stenosed vessels often have more lesions than the severe "index" stenosis, and the majority of infarctions are caused by nonflow-limiting lesions. Because contemporary PCI is limited to the exclusive treatment of flow-limiting lesions, its infarct-preventative effect appears limited. However, improving prognosis in chronic coronary syndromes appears to be linked to infarct prevention (eg, by surgical collateralization) rather than revascularization of chronic ischemic myocardium. Thus, CABG provides superior prognostic outcomes compared with PCI in chronic coronary syndromes because of its collateralization effect. As a consequence, "myocardial revascularization" may not be an appropriate term for summarizing PCI and CABG.

\section{Conflict of Interest Statement}

The authors reported no conflicts of interest.

The Journal policy requires editors and reviewers to disclose conflicts of interest and to decline handling or reviewing manuscripts for which they may have a conflict of interest. The editors and reviewers of this article have no conflicts of interest.

\section{References}

1. Doenst T, Haverich A, Serruys P, Bonow RO, Kappetein P, Falk V, et al. PCI and CABG for treating stable coronary artery disease: JACC review topic of the week. J Am Coll Cardiol. 2019;73:964-76.

2. Knuuti J, Wijns W, Saraste A, Capodanno D, Barbato E, Funck-Brentano C, et al. 2019 ESC guidelines for the diagnosis and management of chronic coronary syndromes. Eur Heart J. 2020;41:407-77.

3. Neumann FJ, Sousa-Uva M, Ahlsson A, Alfonso F, Banning AP, Benedetto U, et al. 2018 ESC/EACTS guidelines on myocardial revascularization. Eur Heart J. 2019;40:87-165

4. Patel MR, Calhoon JH, Dehmer GJ, Grantham JA, Maddox TM, Maron DJ, et al. ACC/AATS/AHA/ASE/ASNC/SCAI/SCCT/STS 2017 appropriate use criteria for coronary revascularization in patients with stable ischemic heart disease: a report of the American College of Cardiology appropriate use criteria task force, American Association for Thoracic Surgery, American Heart Association, 
American Society of Echocardiography, American Society of Nuclear Cardiology, Society for Cardiovascular Angiography and interventions, Society of Cardiovascular Computed Tomography, and Society of Thoracic Surgeons. J Am Coll Cardiol. 2017;69:2212-41

5. Amsterdam EA, Wenger NK, Brindis RG, Casey DE Jr, Ganiats TG, Holmes DR Jr, et al. 2014 AHA/ACC guideline for the management of patients with non-ST-elevation acute coronary syndromes: a report of the American College of Cardiology/American Heart Association task force on practice guidelines. J Am Coll Cardiol. 2014;64:e139-228.

6. Stergiopoulos K, Boden WE, Hartigan P, Möbius-Winkler S, Hambrecht R, Hueb W, et al. Percutaneous coronary intervention outcomes in patients with stable obstructive coronary artery disease and myocardial ischemia: a collaborative meta-analysis of contemporary randomized clinical trials. JAMA Intern Med. 2014;174:232-40.

7. Boden WE, O'Rourke RA, Teo KK, Hartigan PM, Maron DJ, Kostuk WJ, et al. Optimal medical therapy with or without PCI for stable coronary disease. $N$ Engl J Med. 2007;356:1503-16.

8. Al-Lamee R, Thompson D, Dehbi HM, Sen S, Tang K, Davies J, et al. Percutaneous coronary intervention in stable angina (ORBITA): a double-blind, randomised controlled trial. Lancet. 2018;391:31-40.

9. Maron DJ, Hochman JS, Reynolds HR, Bangalore S, O'Brien SM, Boden WE, et al. Initial invasive or conservative strategy for stable coronary disease. $N$ Engl J Med. 2020;382:1395-407.

10. Head SJ, Milojevic M, Daemen J, Ahn JM, Boersma E, Christiansen EH, et al. Mortality after coronary artery bypass grafting versus percutaneous coronary intervention with stenting for coronary artery disease: a pooled analysis of individual patient data. Lancet. 2018;391:939-48.

11. Velazquez EJ, Lee KL, Jones RH, Al-Khalidi HR, Hill JA, Panza JA, et al. Coronary-artery bypass surgery in patients with ischemic cardiomyopathy. $N$ Engl J Med. 2016;374:1511-20.

12. Farkouh ME, Domanski M, Dangas GD, Godoy LC, Mack MJ, Siami FS, et al. Long-term survival following multivessel revascularization in patients with diabetes: the FREEDOM follow-on study. J Am Coll Cardiol. 2019; 73:629-38.

13. Thuijs D, Kappetein AP, Serruys PW, Mohr FW, Morice MC, Mack MJ, et al. Percutaneous coronary intervention versus coronary artery bypass grafting in patients with three-vessel or left main coronary artery disease: 10-year follow-up of the multicentre randomised controlled SYNTAX trial. Lancet. 2019;394:1325-34.

14. Panza JA, Holly TA, Asch FM, She L, Pellikka PA, Velazquez EJ, et al. Inducible myocardial ischemia and outcomes in patients with coronary artery disease and left ventricular dysfunction. J Am Coll Cardiol. 2013;61:1860-70.

15. Bonow RO, Maurer G, Lee KL, Holly TA, Binkley PF, Desvigne-Nickens P, et al. Myocardial viability and survival in ischemic left ventricular dysfunction. $N$ Engl J Med. 2011;364:1617-25.

16. Doenst T, Bargenda S, Kirov H, Moschovas A, Tkebuchava S, Safarov R, et al Cardiac surgery 2019 reviewed. Thorac Cardiovasc Surg. 2020;68:362-75.

17. Jeon C, Candia SC, Wang JC, Holper EM, Ammerer M, Kuntz RE, et al. Relative spatial distributions of coronary artery bypass graft insertion and acute thrombosis: a model for protection from acute myocardial infarction. Am Heart J. 2010;160:195-201.

18. Xaplanteris P, Fournier S, Pijls NHJ, Fearon WF, Barbato E, Tonino PAL, et al. Five-year outcomes with PCI guided by fractional flow reserve. $N$ Engl J Med. 2018:379:250-9.

19. Chikwe J, Sun E, Hannan EL, Itagaki S, Lee T, Adams DH, et al. Outcomes of second arterial conduits in patients undergoing multivessel coronary artery bypass graft surgery. J Am Coll Cardiol. 2019;74:2238-48.

20. Gaudino M, Alexander JH, Bakaeen FG, Ballman K, Barili F, Calafiore AM, et al. Randomized comparison of the clinical outcome of single versus multiple arterial grafts: the ROMA trial-rationale and study protocol. Eur J Cardiothorac Surg. 2017;52:1031-40.

21. Thuesen AL, Riber LP, Veien KT, Christiansen EH, Jensen SE, Modrau I, et al. Fractional flow reserve versus angiographically-guided coronary artery bypass grafting. J Am Coll Cardiol. 2018;72:2732-43.
22. Fournier S, Toth GG, De Bruyne B, Johnson NP, Ciccarelli G, Xaplanteris P, et al. Six-year follow-up of fractional flow reserve-guided versus angiography-guided coronary artery bypass graft surgery. Circ Cardiovasc Interv. 2018;11:e06368.

23. Toth GG, De Bruyne B, Kala P, Ribichini FL, Casselman F, Ramos R, et al. Graft patency after FFR-guided versus angiography-guided coronary artery bypass grafting: the GRAFFITI trial. EuroIntervention. 2019;15:e999-1005.

24. Small GR, Yam Y, Chen L L, Ahmed O, Al-Mallah M, Berman DS, et al. Prognostic assessment of coronary artery bypass patients with 64-slice computed tomography angiography: anatomical information is incremental to clinical risk prediction. J Am Coll Cardiol. 2011;58:2389-95.

25. Chow BJ, Wells GA, Chen L, Yam Y, Galiwango P, Abraham A, et al. Prognostic value of 64-slice cardiac computed tomography severity of coronary artery disease, coronary atherosclerosis, and left ventricular ejection fraction. J Am Coll Cardiol. 2010;55:1017-28.

26. Glineur D, Grau JB, Etienne PY, Benedetto U, Fortier JH, Papadatos S, et al. Impact of preoperative fractional flow reserve on arterial bypass graft anastomotic function: the IMPAG trial. Eur Heart J. 2019;40:2421-8.

27. Glineur D, D'Hoore W, de Kerchove L, Noirhomme P, Price J, Hanet C, et al. Angiographic predictors of 3-year patency of bypass grafts implanted on the right coronary artery system: a prospective randomized comparison of gastroepiploic artery, saphenous vein, and right internal thoracic artery grafts. J Thorac Cardiovasc Surg. 2011;142:980-8.

28. Bonaa KH, Mannsverk J, Wiseth R, Aaberge L, Myreng Y, Nygard O, et al. Drugeluting or bare-metal stents for coronary artery disease. N Engl J Med. 2016;375: 1242-52.

29. Mehta SR, Wood DA, Storey RF, Mehran R, Bainey KR, Nguyen H, et al. Complete revascularization with multivessel PCI for myocardial infarction. $N$ Engl J Med. 2019;381:1411-21.

30. Bates ER. Revisiting reperfusion therapy in inferior myocardial infarction. J Am Coll Cardiol. 1997;30:334-42.

31. Windecker S, Stortecky S, Stefanini GG, da Costa BR, Rutjes AW, Di Nisio M, et al. Revascularisation versus medical treatment in patients with stable coronary artery disease: network meta-analysis. BMJ. 2014;348:g3859.

32. Miller RJH, Bonow RO, Gransar H, Park R, Slomka PJ, Friedman JD, et al. Percutaneous or surgical revascularization is associated with survival benefit in stable coronary artery disease. Eur Heart J Cardiovasc Imaging. 2020;21: 961-70.

33. Bjorklund E, Nielsen SJ, Hansson EC, Karlsson M, Wallinder A, Martinsson A, et al. Secondary prevention medications after coronary artery bypass grafting and long-term survival: a population-based longitudinal study from the SWEDEHEART registry. Eur Heart J. 2020;41:1653-61.

34. Newby DE, Adamson PD, Berry C, Boon NA, Dweck MR, Flather M, et al. Coronary CT angiography and 5-year risk of myocardial infarction. N Engl J Med. 2018;379:924-33.

35. Pinho-Gomes AC, Azevedo L, Ahn JM, Park SJ, Hamza TH, Farkouh ME, et al. Compliance with guideline-directed medical therapy in contemporary coronary revascularization trials. J Am Coll Cardiol. 2018;71:591-602.

36. Waksman R, Di Mario C, Torguson R, Ali ZA, Singh V, Skinner WH, et al. Identification of patients and plaques vulnerable to future coronary events with nearinfrared spectroscopy intravascular ultrasound imaging: a prospective, cohort study. Lancet. 2019;394:1629-37.

37. Collet C, Onuma Y, Andreini D, Sonck J, Pompilio G, Mushtaq S, et al. Coronary computed tomography angiography for heart team decision-making in multivessel coronary artery disease. Eur Heart J. 2018;39:3689-98.

38. Liao L, Kong DF, Shaw LK, Sketch MH Jr, Milano CA, Lee KL, et al. A new anatomic score for prognosis after cardiac catheterization in patients with previous bypass surgery. J Am Coll Cardiol. 2005;46:1684-92.

Key Words: cardiac surgery, coronary artery bypass grafting, mortality, myocardial infarction, percutaneous coronary intervention 


\section{E-References}

E1. Serruys PW, Ong AT, van Herwerden LA, Sousa JE, Jatene A, Bonnier JJ, et al. Five-year outcomes after coronary stenting versus bypass surgery for the treatment of multivessel disease: the final analysis of the Arterial Revascularization Therapies Study (ARTS) randomized trial. J Am Coll Cardiol. 2005;46:575-81.

E2. Park SJ, Ahn JM, Kim YH, Park DW, Yun SC, Lee JY, et al. Trial of everolimuseluting stents or bypass surgery for coronary disease. N Engl J Med. 2015;372: 1204-12.

E3. Kapur A, Hall RJ, Malik IS, Qureshi AC, Butts J, de Belder M, et al. Randomized comparison of percutaneous coronary intervention with coronary artery bypass grafting in diabetic patients. 1-year results of the CARDia (Coronary Artery Revascularization in Diabetes) trial. J Am Coll Cardiol. 2010;55:432-40.

E4. Stone GW, Sabik JF, Serruys PW, Simonton CA, Genereux P, Puskas J, et al. Everolimus-eluting stents or bypass surgery for left main coronary artery disease. N Engl J Med. 2016;375:2223-35.

E5. Stone GW, Kappetein AP, Sabik JF, Pocock SJ, Morice MC, Puskas J, et al. Five-year outcomes after PCI or CABG for left main coronary disease. $N$ Engl J Med. 2019;381:1820-30.

E6. Farkouh ME, Domanski M, Sleeper LA, Siami FS, Dangas G, Mack M, et al. Strategies for multivessel revascularization in patients with diabetes. $N$ Engl J Med. 2012;367:2375-84.

E7. Hueb W, Lopes NH, Gersh BJ, Soares P, Machado LA, Jatene FB, et al. Fiveyear follow-up of the Medicine, Angioplasty, or Surgery Study (MASS II): a randomized controlled clinical trial of 3 therapeutic strategies for multivessel coronary artery disease. Circulation. 2007;115:1082-9.

E8. Makikallio T, Holm NR, Lindsay M, Spence MS, Erglis A, Menown IB, et al. Percutaneous coronary angioplasty versus coronary artery bypass grafting in treatment of unprotected left main stenosis (NOBLE): a prospective, randomised, open-label, non-inferiority trial. Lancet. 2016;388 2743-52.

E9. Ahn JM, Roh JH, Kim YH, Park DW, Yun SC, Lee PH, et al. Randomized trial of stents versus bypass surgery for left main coronary artery disease: 5 year outcomes of the PRECOMBAT study. J Am Coll Cardiol. 2015;65: 2198-206.

E10. SoS Investigators. Coronary artery bypass surgery versus percutaneous coronary intervention with stent implantation in patients with multivessel coronary artery disease (the Stent or Surgery trial): a randomised controlled trial. Lancet. 2002;360:965-70.

E11. Serruys PW, Morice MC, Kappetein AP, Colombo A, Holmes DR Mack MJ, et al. Percutaneous coronary intervention versus coronary-artery bypass grafting for severe coronary artery disease. N Engl J Med. 2009; 360:961-72.

E12. Kappetein AP, Feldman TE, Mack MJ, Morice MC, Holmes DR, Stahle E, et al Comparison of coronary bypass surgery with drug-eluting stenting for the treat ment of left main and/or three-vessel disease: 3-year follow-up of the SYNTAX trial. Eur Heart J. 2011;32:2125-34.

E13. Head SJ, Davierwala PM, Serruys PW, Redwood SR, Colombo A, Mack MJ et al. Coronary artery bypass grafting vs percutaneous coronary intervention for patients with three-vessel disease: final five-year follow-up of the SYNTAX trial. Eur Heart J. 2014;35:2821-30. 
TABLE E1. Information from prospective randomized controlled trials comparing coronary artery bypass grafting and percutaneous coronary intervention used for creating Figure 2

\begin{tabular}{|c|c|c|}
\hline $\begin{array}{c}\text { Trial name } \\
\text { (follow-up period) } \\
\text { (year of publication) }\end{array}$ & New MI PCI (\%) & New MI CABG (\%) \\
\hline \multicolumn{3}{|l|}{ ARTS } \\
\hline $1 \mathrm{y}(2005)^{\mathrm{E} 1}$ & 6.0 & 4.6 \\
\hline 3 y $(2005)^{\mathrm{E} 1}$ & 7.3 & 5.7 \\
\hline $5 \mathrm{y}(2005)^{\mathrm{E} 1}$ & 8.5 & 6.6 \\
\hline \multicolumn{3}{|l|}{ BEST } \\
\hline $2 \mathrm{y}(2015)^{\mathrm{E} 2}$ & 4.8 & 2.7 \\
\hline \multicolumn{3}{|l|}{ CARDia } \\
\hline $1 \mathrm{y}(2010)^{\mathrm{E} 3}$ & 9.8 & 5.7 \\
\hline \multicolumn{3}{|l|}{ EXCEL } \\
\hline 3 y $(2016)^{\mathrm{E} 4}$ & 8.0 & 8.3 \\
\hline 5 y $(2019)^{\mathrm{E} 5}$ & 9.1 & 10.6 \\
\hline \multicolumn{3}{|l|}{ FREEDOM } \\
\hline $2 \mathrm{y}(2012)^{\mathrm{E} 6}$ & 6.7 & 4.7 \\
\hline 5 y $(2012)^{\mathrm{E} 6}$ & 13.9 & 6.0 \\
\hline \multicolumn{3}{|l|}{ MASS II } \\
\hline 5 y $(2007)^{\mathrm{E} 7}$ & 11.2 & 8.3 \\
\hline \multicolumn{3}{|l|}{ NOBLE } \\
\hline $1 \mathrm{y}(2016)^{\mathrm{E} 8}$ & 2.0 & 1.0 \\
\hline 5 y $(2016)^{\mathrm{E} 8}$ & 7.0 & 2.0 \\
\hline \multicolumn{3}{|l|}{ PRECOMBAT } \\
\hline 5 y $(2015)^{\mathrm{E} 9}$ & 2.0 & 1.7 \\
\hline \multicolumn{3}{|l|}{ SoS } \\
\hline 2 y $(2002)^{\mathrm{E} 10}$ & 4.0 & 7.0 \\
\hline \multicolumn{3}{|l|}{ SYNTAX } \\
\hline $1 \mathrm{y}(2009)^{\mathrm{E} 11}$ & 4.8 & 3.3 \\
\hline 3 y $(2011)^{\mathrm{E} 12}$ & 7.1 & 3.6 \\
\hline 5 y $(2014)^{\mathrm{E} 13}$ & 10.6 & 3.3 \\
\hline
\end{tabular}

$M I$, Myocardial Infarction; $P C I$, percutaneous coronary intervention; $C A B G$, coronary artery bypass grafting; $A R T S$, arterial revascularization therapies study; $B E S T$, The Randomized Comparison of Coronary Artery Bypass Surgery and EverolimusEluting Stent Implantation in the Treatment of Patients With Multivessel Coronary Artery Disease; CARDia, coronary artery revascularization in diabetes; EXCEL, Evaluation of XIENCE Versus Coronary Artery Bypass Surgery for Effectiveness of Left Main Revascularization Trial; FREEDOM, Future Revascularization Evaluation in Patients With Diabetes Mellitus: Optimal Management of Multivessel Disease; MASS II, medicine, angioplasty, or surgery study II; NOBLE, The NordicBaltic-British Left Main Revascularisation study; PRECOMBAT, Bypass Surgery Versus Angioplasty Using Sirolimus-Eluting Stent in Patients With Left Main Coronary Artery Disease; SYNTAX, Synergy Between PCI With Taxus and Cardiac Surgery. 